\title{
Outbreak of vancomycin-resistant Enterococcus in a renal transplant unit
}

\section{Dear Editor,}

In hemodialysis units, vancomycin-resistant Enterococcus (VRE) colonization is common, probably associated with vancomycin use and the characteristics of these patients. This panorama of colonization is also found in renal transplant units (RTU). ${ }^{1}$ However, epidemiological data including risk factors associated with colonization or infection due to VRE in this population are scanty. Here, we describe an outbreak and the measures used to eradicate VRE in a RTU.

The outbreak took place in a RTU of a 700-bed University Hospital in Curitiba (PR, Brazil). The first case of VRE in this hospital was described in 2004 and the percentage of VRE infection has been between $1.16 \%$ and $2.4 \%$.

In March 1, 2009 the first case of VRE in the RTU was reported. Thus, three samples of rectal swabs were obtained from all patients admitted to the unit. Three patients turned out positive and one patient was negative in the first day. In the second week, two cases of VRE colonization were found and one patient had a negative culture. In the third week, one of eight patients was positive. In the fourth week one out of six patients was positive. Since then, no other patient with VRE was found in the RTU. Surveillance was discontinued after four months of continuous vigilance. During the outbreak, a total of eight patients were found to be colonized and one patient was infected (urinary tract infection) from a total of 33 patients screened in the unit. Environmental samples, such as beds, clothes, walls, tables, chairs, doors, doorknobs, stretcher, mattresses, pillows, and several other objects were all negative. Cultures from the hands of healthcare workers were also negative.

Vancomycin resistance was confirmed using Kirby-Bauer disk diffusion and the E-test. ${ }^{2}$

PCR to detect VRE resistance genes was performed following Petrich et al., ${ }^{3}$ which amplified the vanA gene in all strains of
Enterococcus faecium. Pulsed-field electrophoresis, described elsewhere, demonstrated a predominant genotype. ${ }^{4}$ Genotype A and its subtype A1 were found in the RTU, and genotype $\mathrm{B}$ was found in patients from other units.

A case-control study was performed. Cases included all VRE colonized/infected patients from the RTU. Controls were patients with three rectal swabs negative for VRE admitted during the same period (four months) to the unit. Clinical data were extracted from the medical records and are described in the Table 1. Duration of hospitalization and previous use of ceftriaxone were risk factors for VRE in the univariate analysis. Ceftriaxone was an isolated risk factor for VRE in the binary regression $(\mathrm{p}=0.029)$, demonstrating an $\mathrm{OR}=8.8(95 \%$ CI: 1.25-62.20).

An educational program about VRE was implemented following published guidelines. ${ }^{5}$ The major focus of the education program was to enforce healthcare workers to adhere to contact isolation guidelines: I) wear of gown; II) use of gloves; III) hand hygiene using alcohol gel before and after any patient manipulation. Daily bath with chlorhexidine was done for all patients as an additional measure to control the outbreak. All material (clothes, pillows etc) used by patients were separated in plastic bags to further sterilization (autoclave or ethylene oxide).

Previous use of third generation cephalosporins was the only independent risk factor for VRE colonization in this outbreak. Although vancomycin has always been described as risk factor for VRE, third generation cephalosporins have also been nailed down in small series. ${ }^{6,7}$

Costs related to VRE infection can exceed three times the average admission. ${ }^{8}$ In addition to extra cost, there is the risk of developing of an endemic status of VRE. In our study, intensive measures were effective to control the outbreak. The
Authors

Felipe Francisco Tuon ${ }^{1}$ Sergio Ricardo PenteadoFilho $^{2}$

Janaina Camilotti ${ }^{3}$ Inneke Marie van der Heijden ${ }^{4}$

Silvia Figueiredo Costa ${ }^{5}$

${ }^{1} \mathrm{MD}, \mathrm{PhD}$; Professor,

Division of Infectious and Parasitic Diseases, Hospital Universitário Evangélico de Curitiba, Curitiba, PR, Brazil

${ }^{2} \mathrm{MD}$; Division of Infectious and Parasitic Diseases, Hospital Universitário Evangélico de Curitiba, Curitiba, PR, Brazil ${ }^{3}$ MPharm, Hospital Universitário Evangélico de Curitiba, Curitiba, PR, Brazil

${ }^{4} \mathrm{PhD}$, Department of Infectious Diseases and LIM-54, Universidade de São Paulo, SP, Brazil ${ }^{5} \mathrm{MD}, \mathrm{PhD}$; Department of Infectious Diseases and LIM-54, Universidade de São Paulo, SP, Brazil

Submitted on: 11/25/2010 Approved on: 01/3/2011

Correspondence to: Felipe Francisco Tuon Infectious and Parasitic Diseases Clinic Hospital Universitário Evangélico de Curitiba Alameda Augusto Stellfeld 1908, $3^{\circ}$ andar - SCIH, Bigorrilho 80730-150 Curitiba, Brazil flptuon@gmail.com

We declare no conflict of interest.

(C2011 Elsevier Editora Ltda. All rights reserved. 
Table 1. Case control study of patients colonized/infected with VRE during an outbreak

\begin{tabular}{|c|c|c|c|}
\hline Variable & $\begin{array}{l}\text { VRE positive } \\
\quad(\mathrm{n}=9)\end{array}$ & $\begin{array}{l}\text { VRE negative } \\
\quad(\mathrm{n}=24)\end{array}$ & p-value \\
\hline Age (median with range) & $36(15-49)$ & $37(8-70)$ & NS \\
\hline Gender (male \%) & $55.55 \%$ & $58.33 \%$ & NS \\
\hline Admission duration (mean \pm SD) & $16.11 \pm 15.71$ & $7.65 \pm 3.90$ & 0.018 \\
\hline $\mathrm{DM}$ & $0.00 \%$ & $4.16 \%$ & NS \\
\hline ICC & $11.11 \%$ & $4.16 \%$ & NS \\
\hline HAS & $25.00 \%$ & $33.33 \%$ & NS \\
\hline Intensive care unit & $0.00 \%$ & $4.16 \%$ & NS \\
\hline Surgery & $11.11 \%$ & $20.83 \%$ & NS \\
\hline Neoplasm & $0.00 \%$ & $0.00 \%$ & NS \\
\hline Under dialysis & $11.11 \%$ & $8.32 \%$ & NS \\
\hline Cyclosporine & $22.22 \%$ & $20.83 \%$ & NS \\
\hline Mophethyl-mycophenolate & $100.00 \%$ & $95.83 \%$ & NS \\
\hline Tacrolimus & $77.77 \%$ & $54.13 \%$ & NS \\
\hline Prednisone & $100.00 \%$ & $95.83 \%$ & NS \\
\hline Azathioprine & $0.00 \%$ & $0.00 \%$ & NS \\
\hline Urinary catheter & $11.11 \%$ & $29.16 \%$ & NS \\
\hline Previous renal transplant & $22.22 \%$ & $4.16 \%$ & NS \\
\hline \multicolumn{4}{|l|}{ Previous antibiotic use } \\
\hline Ceftriaxone & $44.44 \%$ & $8.32 \%$ & 0.034 \\
\hline Cefepime & $11.11 \%$ & $0.00 \%$ & NS \\
\hline Carbapenem & $0.00 \%$ & $0.00 \%$ & NS \\
\hline Piperacillin-tazobactam & $0.00 \%$ & $0.00 \%$ & NS \\
\hline Vancomycin & $22.22 \%$ & $0.00 \%$ & 0.068 \\
\hline Metronidazole & $0.00 \%$ & $0.00 \%$ & NS \\
\hline Mortality & $0 \%$ & $4.10 \%$ & NS \\
\hline
\end{tabular}

NS, non-significant.

infection control activities to tackle the outbreak were extended to four months, a decision based on previous studies, which showed recurrence when carried out for only two months. ${ }^{9,10}$

Adherence to all measures of isolation and use of alcohol gel are enough to control a VRE outbreak, including cohort in larger units. ${ }^{11}$ Some authors demonstrated that even with all measures applied, VRE can become endemic in the hospital. ${ }^{12}$ Guidelines are available but we believe that the most important in an outbreak is the continuous and intensive staff education. ${ }^{13}$

Daily chlorhexidine bathing decreases the incidence of colonization by Gram-positive cocci, but its use as a measure of control of VRE outbreak has not been described. Skin colonization is a major source of VRE and reduction in the VRE acquisition rate reduces the colonization pressure. ${ }^{14}$
This study contributes to the understanding of the epidemiology dynamics of a VRE outbreak in RTUs and highlights infection control measures that can be useful in the control of VRE spread.

\section{REFERENCES}

1. Freitas MC, Pacheco-Silva A, Barbosa D et al. Prevalence of vancomycin-resistant Enterococcus fecal colonization among kidney transplant patients. BMC Infect Dis 2006; 6:133.

2. Clinical and Laboratory Standards Institute. Performance Standards for Antimicrobial Susceptibility Testing. Clinical and Laboratory Standards Institute. Fifteenth Informational Supplement. 2005. Pennsylvania, USA. Ref Type: Serial (Book,Monograph) 
3. Petrich AK, Luinstra KE, Groves D et al. Direct detection of $v a n \mathrm{~A}$ and $v a n \mathrm{~B}$ genes in clinical specimens for rapid identification of vancomycin resistant enterococci (VRE) using multiplex PCR. Mol Cell Probes 1999; 13:275-81.

4. Tenover FC, Arbeit RD, Goering RV et al. Interpreting chromosomal DNA restriction patterns produced by pulsed-field gel electrophoresis: criteria for bacterial strain typing. J Clin Microbiol 1995; 33:2233-9.

5. Muto CA, Jernigan JA, Ostrowsky BE et al. SHEA Guideline for Preventing Nosocomial Transmission of MultidrugResistant Strains of Staphylococcus aureus and Enterococcus. Infect Control Hosp Epidemiol 2003; 24:362-86.

6. Carmeli Y, Eliopoulos GM, Samore MH. Antecedent treatment with different antibiotic agents as a risk factor for vancomycin-resistant Enterococcus. Emerg Infect Dis 2002; 8:802-7.

7. Askarian M, Afkhamzadeh R, Monabbati A et al. Risk factors for rectal colonization with vancomycin-resistant enterococci in Shiraz, Iran. Int J Infect Dis 2008; 12:171-5.

8. Muto CA, Giannetta ET, Durbin LJ et al. Cost-effectiveness of perirectal surveillance cultures for controlling vancomycinresistant Enterococcus. Infect Control Hosp Epidemiol 2002; 23:429-35.
9. Aumeran C, Baud O, Lesens O et al. Successful control of a hospital-wide vancomycin-resistant Enterococcus faecium outbreak in France. Eur J Clin Microbiol Infect Dis 2008; 27(11):1061-4.

10. Schmidt-Hieber M, Blau IW, Schwartz S et al. Intensified strategies to control vancomycin-resistant enterococci in immunocompromised patients. Int J Hematol 2007; $86: 158-62$.

11. Ott M, Wirick H. Vancomycin-resistant enterococci (VRE) and the role of the healthcare worker. Can Oper Room Nurs J $2008 ; 26: 21-9,32$.

12. Kurup A, Chlebicki MP, Ling ML et al. Control of a hospital-wide vancomycin-resistant enterococci outbreak. Am J Infect Control 2008; 36:206-11.

13. Peta M, Carretto E, Barbarini D et al. Outbreak of vancomycin-resistant Enterococcus spp. in an Italian general intensive care unit. Clin Microbiol Infect 2006; 12:163-9.

14. Vernon MO, Hayden MK, Trick WE et al. Chlorhexidine gluconate to cleanse patients in a medical intensive care unit: the effectiveness of source control to reduce the bioburden of vancomycin-resistant enterococci. Arch Intern Med 2006; 166:306-12. 